CHAPTER 1

\title{
Reference and Quantification in Nominal Phrases: The Current Landscape and the Way Ahead
}

\author{
Chiara Gianollo, Klaus von Heusinger and Maria Napoli
}

The thematic volume 'Determiners and quantifiers: Functions, variation, and change' explores the interface between morphosyntax and semantics-pragmatics in the domain of referential and quantificational nominal expressions. We present case studies from Romance and Germanic languages, dealing with both synchronic and diachronic aspects. Our aim is to empirically test, on the basis of comparative data, the most recent theoretical developments in the analysis of reference and quantification and to identify focal points for future research.

Formal syntax and semantics have long abandoned the idea that referential and quantificational expressions may receive a uniform characterization (say, 'Determiner Phrase' as concerns syntax and 'Generalized Quantifier' as concerns semantics), and have explored a number of dimensions of variation. This work, however, has not yet managed to reach a general, consensual framework delimiting in a principled way the dimensions of cross-linguistic variation at the interface between meaning and form (for recent representative attempts in this direction see the volumes edited by Stark, Leiss and Abraham 2007, Cabredo Hofherr and Zribi-Hertz 2014, Aguilar-Guevara, Pozas Loyo and Vázquez-Rojas Maldonado 2019, Balogh, Latrouite and Van Valin 2020). A further gap in our knowledge is represented by the scarcity of diachronic studies exploring the validity of certain theoretical proposals on the basis of the actual developmental tendencies of referential and quantificational expressions in documented historical stages of languages.

Current theoretical work has developed models that envisage a more transparent mapping between meaning and form in nominal phrases, but also in determiners and quantifier words themselves, thanks to a more detailed study of word-internal compositionality, as well as of diachronic processes affecting it. This work has substantially benefited from a renewed attention to conditions on language use, which has led to a closer investigation of pragmatic factors interacting with semantics and of the behavior of nominal phrases in discourse. 
This volume brings together experts in syntax, semantics, and pragmatics in order to cooperatively work on filling the gaps highlighted above, and to systematically pursue an improved integration of syntax, semantics, and pragmatics. The chapters in this collection are motivated by the same fundamental research questions and by the methodological focus on synchronic variation and diachronic change as a source of crucial evidence to validate our theoretical models of the interfaces between the structural and the interpretative component. Each chapter contains a contribution to the theoretical analysis of the phenomenon at stake, informed by the contemporary discussion in formal syntactic and semantic frameworks, as well as by typological generalizations. The chapters variously contribute to three fundamental areas in the study of reference and quantification: reference and quantification between morphosyntax and interpretation; reference and quantification in discourse; reference and quantification in diachrony. In this introductory contribution, we single out some outstanding issues for each of these areas, and we provide an overview of the insights emerging from the studies collected in this volume. Before we focus on the three areas listed above, we will start with a more general section on interface issues between morphosyntax and semantics in the domain of reference and quantification.

\section{2 \\ Interface Issues}

A first obstacle to overcome in an integrated approach to the morphosyntax and the interpretation of referential and quantificational expressions is a terminological one (on which see also Panagiotidis 2018). As is often the case, terminological mismatches between (sub)disciplines are the symptom of deeper differences in the way of conceptualizing phenomena and research questions, which are scrutinized in this volume.

In theoretical syntax, the classification of elements contributing referential or quantificational functions is fundamentally based on their distribution, that is, mainly on their patterns of positioning with respect to the nominal nucleus and of co-occurrence with other functional elements of the lexicon. Most generative work on the nominal domain rests on the so-called DP hypothesis (Szabolcsi 1983, 1987, Abney 1987, Horrocks and Stavrou 1987, Stowell 1989, 1991, Longobardi 1994): nominal phrases are headed by determiners; that is, functional items of the lexicon project their own structure, the Determiner Phrase, which embeds the noun's projection NP. The DP hypothesis is rooted in the attempt of X-bar-theoretic syntax to explain syntactic structures by means of one general template that applies across categories: according to this view, 
CPs (full clauses) are structurally parallel to DPs (nominals) in having a lexical core that is embedded into nested projections of grammatical categories (the so-called 'extended functional projections', since Grimshaw's seminal work in the 199os, published as Grimshaw 2005: chapter 1). ${ }^{1}$

The DP hypothesis has a number of ramifications on which there has always been less consensus in the literature; they are discussed at various points in the present collection.

The universality of a DP projection has been questioned, given the existence of languages without articles. The absence of articles has been argued to correlate with other syntactic properties pointing to the absence of a DP projection (Bošković 2008, 2012). In a more semantically-driven perspective, a semantic parameter has been proposed, according to which in some languages $\mathrm{NPs}$ would be inherently predicates, and need D to turn them into arguments, whereas in other languages NPs would be inherently of an argumental type (referential names of kinds), with no need for a D projection (Chierchia 1998). Related to this cross-linguistic issue, a further point concerns the analysis of determinerless nominal phrases (bare nouns) in languages that do have articles (see Alexiadou, this volume), which has led to the much-discussed assumption of empty determiners, that is, syntactically and semantically present but phonetically null Ds (Longobardi 1994, 2001). The debate on bare nouns, in turn, branches out into the study of noun incorporation and pseudo-incorporation (on which see Dayal 2011, Borik and Gehrke 2015) and the study of the principles governing the alternation between bare and non-bare forms (for instance, with partitives or generics, as amply discussed in this volume; see also Kabatek and Wall 2013 and recently Ihsane 2021).

A separate aspect of the DP hypothesis that is a source of substantial differences across syntactic analyses concerns the way in which semantic-pragmatic concepts are argued to be mirrored by the syntax of nominal phrases: as also happens with clausal syntax (on which see the discussion in Leonetti, this volume), more elaborate treatments tend to enrich the functional structure in order to syntactically represent all meaningful elements, comprising information-structural notions, whereas more reductionist analyses restrict the number of syntactically encoded categories and operations.

1 This parallelism has recently been questioned by Chomsky, Gallego and Ott (2019) for theoretical reasons connected to the understanding of syntactic structure building under a Bare Phrase Structure approach, which, more in general, are leading to re-thinking the notion of projection itself (on which see Borer 2005: chapter 1). Another line of criticism addresses asymmetries between DPs and CPs in terms of selection and featural dependencies: for opposing positions in the debate surrounding these aspects see Bruening, Dinh and Kim (2018) and Larson (2019). 
Thus, depending on the theoretical framework, proposals vary as to how rich, in terms of categorial projections, the functional extended structure of nominals is assumed to be, and as to how universal this structure is (a longstanding debate summarized in Alexiadou, Haegeman and Stavrou 2007).

On the basis of distributional properties, in some generative treatments, a class of determiners is distinguished from a class of quantifiers (Shlonsky 1991, Stowell 1991, Cardinaletti and Giusti 1991, Giusti 1991). ${ }^{2}$ Accordingly, different projections (and different positions within such projections) are posited for these elements: an article is considered to be the head of the DP projection, whereas quantifiers are analyzed as heads or specifiers of a hierarchically higher Quantifier Phrase QP, accounting this way for their possible cooccurrence, as in all $_{\mathrm{Q}}$ the $e_{\mathrm{D}}$ students. ${ }^{3}$ Matthewson (2001) shows that in the Salish language St'át'imcets QPs systematically take DPs (of type e), and not NPs (of type $\langle\mathrm{e}, \mathrm{t}\rangle$ ), as their complement. In an attempt to reach cross-linguistic uniformity for the denotation of quantifiers, she proposes that also in structures of English like all cats the quantifier takes a DP with a phonetically empty head as a complement $\left(\right.$ all $\emptyset_{\mathrm{Q}}$ cats $)$.

When we move to semantic theories, we see that the attention obviously shifts towards the interpretative component, traditionally with less attention to the distributional patterns within the nominal phrase. In this perspective, the distinction between determiners and quantifiers that is routinely made in syntactic analyses does not easily match the categorization of functional items based on their semantic properties. The main distinction made from a semantic perspective is, rather, one between referential and quantificational expressions.

In original formulations, such as e.g. Stowell (1991), the syntactic differentiation between DPs and QPs was meant to match this distinction: the idea, based on Higginbotham's (1985) proposal that determiners are needed in order to turn nominal predicates into arguments, was that DPs can be used as referential arguments of type e, whereas QP s are those nominal phrases that do not appear in argument position in the logical structure, since they have to undergo quantifier raising (Generalized Quantifiers of type $\langle\langle\mathrm{e}, \mathrm{t}\rangle, \mathrm{t}\rangle$; see Barwise and Cooper 1981, Keenan and Stavi 1986). However, the class of semantically quan-

2 Hence, the term 'determiner' becomes ambiguous between a broader reading, encompassing quantifiers as a subclass, and a narrower reading, excluding quantifiers as a separate category.

3 Note here that in syntactic jargon the term 'quantifier' refers to the item of the functional lexicon (e.g. every), while in semantic jargon it refers to the denotation of the entire QP, that is, of the nominal expression containing the functional item and its restriction (generalized quantifiers like e.g. nothing, every cat). 
tificational expressions is broader than the class of nominal phrases for which a QP projection is routinely posited in the syntax and, conversely, the class of referential expressions does not coincide with the class of nominal phrases containing the DP projection: in current practice there are often pervasive mismatches between syntactic categories and semantic types. ${ }^{4}$

This mismatch is deeply entrenched in the conceptualization of the definite and indefinite article. In syntactic representations, definite and indefinite articles have often been treated alike and considered heads of the DP projection. This analysis is entailed by syntactic approaches that see $\mathrm{D}$ as the position that hosts a binary feature [ \pm definite] (e.g. Lyons 1999) and by analyses that require $\mathrm{D}$ to be overtly filled in some languages and treat the indefinite article as an appropriate filler (e.g. Longobardi 1994). From a semantic point of view, however, definite and indefinite articles differ substantially in their semantic function, mirrored in terms of their semantic types. The definite article is a function from a (singleton) set to the element of that set, that is, it is defined in terms of the type $\langle\langle\mathrm{e}, \mathrm{t}\rangle, \mathrm{e}\rangle$ and yields a referential reading of the DP (i.e., type e). The indefinite article, on the other hand, under a quantificational analysis, denotes a relation between two sets (a function from sets to sets of sets $(\langle\langle\mathrm{e}, \mathrm{t}\rangle\rangle,\langle\langle\mathrm{e}, \mathrm{t}\rangle, \mathrm{t}\rangle))$. Following this analysis, an indefinite nominal phrase is of type $\langle\langle$ e,t $\rangle, t\rangle$, i.e., the type of a QP. ${ }^{5}$

Indeed, since the beginning of the DP hypothesis, various proposals have been advanced in order to distinguish also syntactically between the definite and the indefinite article. Abney (1987: 222), for instance, discusses some advantages of interpreting the English indefinite article $a$ as something other than a determiner, recalling Perlmutter's (1970) proposal to treat it as the reduced form of the cardinal numeral one (see also Kayne 1994: 124). Lyons (1999: 89-95) highlights the typological rarity of 'real indefinite articles', understood as encoding the [- Def] feature in D, and supports an analysis of English

4 The extent and nature of these mismatches, besides being dependent on the specific syntactic framework adopted, also vary across semantic theories. For instance, Montague's (1973) model avoids them by positing a uniform semantic denotation for all nominal expressions in terms of generalized quantifiers (see Williams 1983 and Higginbotham 1985 for early counterarguments). Russell (1905) treats definite descriptions as quantificational expressions, as further discussed in the main text. Discourse Representation Theory (since Kamp 1981) and File Change Semantics (Heim 1982) opt for a non-quantificational representation of indefinite nominals.

5 The quantificational analysis is only one possible semantic approach to the indefinite article, as we will see below in this section and in Section 4. See also the discussion of type flexibility with the definite and the indefinite article and of possible type-shifting operations in Partee (1987). 
$a$ as a cardinality term. In current syntactic research, various models have been proposed in which definite and indefinite articles are considered to be firstmerged in the structure at different points (see Zamparelli 2000, Borer 2005 and Klockmann 2020 also for a useful overview of past proposals).

Famously, there is a controversy surrounding the semantic type of definite descriptions and there exist quantificational treatments of definite descriptions, which could result in a more uniform syntax-semantics mapping. Russell (1905) assumes that definite descriptions like the king of France are quantifier phrases, i.e. of type $\langle\langle\mathrm{e}, \mathrm{t}\rangle, \mathrm{t}\rangle$. This non-referential type allows to interpret the sentence The king of France is bald as false, and it allows to model scope interactions. However, Strawson (1950) takes definite descriptions as referential expressions of type e with a uniqueness presupposition, and assumes that the sentence above causes a presupposition failure. While this controversy is not yet resolved, a majority of semantic analyses follow Strawson, matching the syntactic analysis of definite descriptions as DPs.

Moreover, various observations on contexts with non-prototypical functions of articles cast doubts on the possibility of attributing them a uniform semantic and syntactic characterization.

For example, not all instances of what is morphosyntactically a definite article ultimately yield a referential expression. So-called weak definites are syntactically DPs, but semantically do not imply global uniqueness and behave more like indefinite nominal phrases (Carlson et al. 20o6, Schwarz 20o9; see also Borik and Gehrke 2015 for the semantic parallels with pseudo-incorporation). In some languages, singular and plural definite articles receive generic interpretation (Longobardi 1994, 2001, Borik and Espinal 2012, Barton, Kolb and Kupisch 2015).

As for indefinite articles, their semantic import differs (and, consequently, receives different representations, in ways that vary across frameworks) depending on a number of factors, in particular the surrounding linguistic environment and the competition with alternative indefinite expressions in a given language. The most stable semantic contrast we find cross-linguistically is that between a specific (referential) and non-specific (existential) interpretation of a nominal phrase containing an indefinite article (see Fodor and Sag 1982, Diesing 1992, von Heusinger 2002, 2011 and Schwarzschild 2002). ${ }^{6}$

6 Proposals to encode these differences in the syntactic component can be found among others in Zamparelli (2000) and Ihsane (2008). 


\section{Reference and Quantification between Morphosyntax and} Interpretation: Articles

Articles represent a particularly thorny domain for the morphosyntax-semantics interface: in this collection, they are discussed from multiple angles in various contributions. Alexiadou's contribution is dedicated to the role of the definite article in plural generic nominals, based on a comparison between Germanic and Romance. Squartini's chapter deals with the system of Romance indefinite articles. Petrova presents a diachronic study on the role of indefinite articles in German nominal predicates.

The chapter by Alexiadou, 'Definite plural generics in English: evidence from de-adjectival nominalization', provides a fresh look on the outstanding issue of plural nominal phrases with a generic reading. She discusses differences and similarities between Romance and English, with a focus on the article + adjective combinations like the poor.

Since Carlson (1977), a lot of attention has been devoted to the interpretation of bare plurals in English, and to the cross-linguistic difference with respect to Romance, where (plural) bare nouns are impossible in some languages and severely restricted in others. In the specific case of plural kind and generic interpretation, Spanish and Italian invariantly need the definite article (It. I cani sono intelligenti vs. Engl. Dogs are clever), whereas in English an analogous structure (The dogs are clever) is interpreted as denoting a contextually given maximal set.

This cross-linguistic dichotomy breaks down once cases are considered where plural definites can be used with a generic meaning also in English. Among those we find anaphoric generics (Saurischian Bipeds ... The saurischians ...), instances in dialectal varieties and previous historical stages of English (on which see also Section 6), and, crucially for Alexiadou's analysis, article + adjective combinations (the poor but also the youngs), where the definite article is in fact the only option to obtain a generic reading. Alexiadou argues for a competition scenario involving definite plural generics and bare plurals in Present Day English, whereby the constrained appearance of definite plural generics is due to the presence of an alternative formal realization for genericity that is structurally simpler: bare nouns, following Borer (2005), are simpler because they lack the quantity phrase \#P (with a counting, individualizing function). Where this bare alternative realization is absent, i.e., in the case of adjectival nominalizations, the definite article's potential to contribute a generic meaning is unconstrained, and English converges with Romance. The difference between English and French in the overall availability of the barenoun strategy is connected to the different properties of number marking in the two languages (on which see Section 6). 
According to Alexiadou's analysis, in definite generics the quantity phrase \# $\mathrm{P}$ is projected: the definite article merges there and raises to $D$. This has semantic consequences: Alexiadou argues that the generic meaning expressed by plural definites differs semantically from the genericity expressed via bare nouns, since the definite article contributes maximality, as in a prototypical definite reading. Genericity is thus obtained by creating a maximal sum of individuals that is not contextually constrained. The fact that different formal ways to obtain a generic meaning correspond to semantically distinct shades of genericity is a point highlighted also by Leonetti (1999: 870-882), in surveying the various forms of generic nominals in Spanish.

Moving to indefinite articles, Squartini's specific focus in his chapter, 'Quantification and classification in Romance plural indefinites: from Number to Seinsart?', is on the paradigm of Romance indefinite articles and, especially, on the differing realizations of plural indefinites. In order to develop his account, Squartini provides a comprehensive overview of the intricate relations between classificational aspects and number marking in French, Italian and Spanish, which connects well also with Alexiadou's discussion of the syntactic role of number marking. Squartini's considerations on the role of number marking are also backed up by the analysis of the Piedmontese koiné, an ItaloRomance variety with a particularly impoverished number morphology.

Classificational distinctions in the denotation of nominal phrases concern qualitative properties of nominals such as the count-mass distinction (what Rijkhoff 2002 terms Seinsarten). Different conceptualizations of masses and pluralities in the literature lead to different understandings of the relation between the two, at the interface between cognition and grammar: once masses are understood not as homogeneous substances but as inherently composed of portions, their intrinsic cumulativity draws them nearer to plurals. This opens up new perspectives of analysis for determiner systems, and in particular for the paradigm of indefinite articles.

The opposition observed in French between indefiniteness marking in singular count (un) and mass nouns (de + number marking) hints at the role of classificational aspects in the article system. ${ }^{7}$ The issue is, then, whether classificational aspects have a role in the plural as well. On the basis of the assumption of a strict form-function correlation, whereby morphological relatedness is equivalent to semantic relatedness, it has indeed been proposed for Romance that the different forms for the plural indefinite article (e.g. French and Italian

7 Squartini follows Cardinaletti and Giusti (2018) in considering the so-called partitive article as an element of the $\mathrm{D}$ projection. See the contributions in Ihsane (2021) for a comprehensive perspective on the debate concerning this issue. 
'partitive' article $d e$-vs. Spanish morphological plural of un-) may correspond to different classificational meanings of the plural ("the way in which referents are combined together", in Squartini's phrasing): the plural of the partitive would have a mass-like interpretation, creating homogeneous aggregates, while the plural of un- would have a 'collective' meaning, crucially with non-distributive readings.

Squartini rejects this view on the basis of both empirical data and theoretical considerations. From his perspective, while different classificational aspects may have played a role in the grammaticalization process, a deep similarity in the resulting paradigmatic structure of contemporary Romance indefinite determiners emerges, which goes beyond the more superficial morphosyntactic differences: the governing principle is the preservation of a formal distinction between singular and plural, independently of the strategies employed by each language. Mass and plural are kept distinct in each language and the classificational aspects are always mediated by number, meaning that plural articles never have a genuinely classificational function in Italian, Spanish and French. Nonetheless, one can observe grammaticalization phenomena in which classification is a more prominent shaping factor (on which see further Section 6).

Indefinite articles are also at the core of Petrova's contribution 'Bare and indefinite nominal predicates in the history of German'. In her study, however, the attention shifts from argumental uses to predicative ones. The appearance of (indefinite or definite) articles in predicative expressions is hard to explain by the approaches, seen in Section 2, that consider $\mathrm{D}$ as a category that turns a predicate into an argument (see Williams 1983: 424 for the assumption that predicate nominals "are syntactically identical to referential noun phrases" although they have a different logical type). While it is technically possible to obtain the right semantic type by postulating type-shifting operations (Partee 1987), the functional motivation for the alternation between the presence and the absence of the article is much debated, also in consideration of the differing conditions to which this alternation is subject in various languages, and at different diachronic stages. Furthermore, early treatments (Stowell 1989, 1991) already remarked that not all nouns behave in the same way with respect to their acceptability as bare predicates in various constructions: nouns for professions (doctor) or appointments (president) stand out both intra- and crosslinguistically for their readiness to be used as bare predicates (see Zamparelli 2008 for a comparative study of bare predicate nominals in Romance).

Petrova takes these empirical facts as her starting point and investigates the factors allowing for bare and 'indefinite' nominal predicates with copula verbs at various diachronic stages of German, and also across dialectal varieties. 
We will present the aspects that specifically pertain to the diachronic import of the phenomenon in Section 6. For now, let us comment on how Petrova's diachronic study of the formal alternation ties in with her synchronic analysis.

Semantically, she shows how uniqueness strongly correlates to the availability of the bare realization at all historical stages of German; what changes, due to language-external reasons, is the inventory of nouns belonging to the class of individual-identifying nouns denoting a unique function ('role nouns', such as 'bishop', 'treasurer', 'judge', as opposed to property-identifying nouns such as 'hero', 'giant', 'idiot').

Syntactically, she proposes that the predicative phrase is a DP also when it is articleless, and that role nouns, in virtue of their individual-identifying function, behave as proper names (under Longobardi's 1994 analysis): they are able to raise to the position of an empty determiner $\left.{ }_{\mathrm{D}} e\right]$ (in languages that have evidence for such an empty category), accounting this way for the absence of a determiner in the $\mathrm{D}$ position, which ends up being occupied by the noun.

According to Petrova, this model not only accounts for the behavior of predicative noun phrases in the oldest stages of German, but can also explain the situation observed in Present Day German, with a gradually increasing number of nouns conceptualized as role nouns. In this respect, a further factor, this time language-internal, that is subject to diachronic change emerges from the study of non-standard varieties: the almost complete loss of predicative bare nouns in some Upper German dialects is a consequence of the loss of the possibility of licensing $\left[{ }_{\mathrm{D}} e\right]$ and, as a result, the loss of N-to-D movement. This makes the presence of a determiner with predicative role nouns obligatory.

\section{$4 \quad$ Reference and Quantification between Morphosyntax and Interpretation: Indefinites}

The rich variety in shape and function of indefinite determiners in natural languages has attracted the attention of formal linguists, comparatively and typologically oriented scholars, and historical linguists alike. The fundamental questions concern, on the one hand, the functional drive behind such a remarkable pool of options to express existential quantification: just to give an example, Haspelmath's (1997) semantic map of English indefinites counts four main series of 'specialized' indefinite pronouns (some, any, no, wh-ever), to which also multi-word combinations like a certain, besides the indefinite article, can be added. On the other hand, a pervasive multifunctionality of indefinite determiners is observable in many languages: just to mention some much-discussed examples, any notoriously has a free-choice or a negative-polarity interpreta- 
tion, the indefinite article can have specific and non-specific readings, and so on. In our collection, four contributions investigate indefinites from various angles.

One major aspect of the debate is how to best characterize indefinites as formal semantic objects, encompassing also their discourse contribution (on which see further Section 5). In recent years, frameworks like Alternative Semantics and Inquisitive Semantics have shaken up the terms of the discussion, by adding new formats for representing indefinites to the more traditionally discussed ones (Generalized Quantifiers, DRT-style variables, choice functions). In this collection, Aloni shows how an analysis of free-choice indefinites in terms of Alternative Semantics is able to insightfully account not only for their synchronic distribution, but also for their diachronic evolution. Onea presents a novel theory of the discourse contribution of special indefinites, the 'erotetic theory of indefinites', which is based on Inquisitive Semantics and on the discourse view elaborated in the Question under Discussion approach.

The Alternative Semantics analysis developed by Aloni in her contribution 'Indefinites as fossils: the case of wh-based free choice' is based on the hypothesis, stemming from Kratzer and Shimoyama's (2002) work, that indefinites closely resemble questions in their potential to evoke propositional alternatives: an indefinite like someone, when composed into a proposition, generates a set of alternative propositions (e.g., for someone called, propositions like $x$ called, $y$ called, $z$ called, etc.). This set of alternatives interacts with abstract operators in the clause, yielding different semantic contributions depending on the operator quantifying over the alternatives. For instance, the alternatives generated by someone in an episodic sentence will be bound by an operator with existential quantificational force. The existence of different specialized indefinite lexemes would then be accounted for by assuming that these specialized forms encode the necessity for a given indefinite to be associated with an operator of a certain kind in order to be felicitous. For instance, negatively marked indefinites will encode the need for a negative operator to license them. Aloni explores in particular the conditions imposed on the surrounding semantic context by free-choice indefinites like Spanish cualquier and Dutch wie dan ook; moreover, she investigates how their enriched meaning contribution emerged historically, finding a link between the contemporary conditions of use and the original morphology and distribution (see further Section $6)$.

Onea's contribution 'Specificity and questions of specification' provides a conceptually different perspective, which is based on his discourse-oriented 'erotetic theory of indefinites'. According to this theory an indefinite makes three different contributions: i) it raises a question that needs an answer, ii) the 
lexical contribution of special indefinites makes a comment on how this question can be answered (e.g. indicates that the speaker knows the answer); iii) these comments on the answer determine the scopal properties of the indefinite. For example, the German special indefinite ein gewisser $N$ ('a certain N') raises the specificational question which $N$ ? The contribution of the specialized indefinite is that the speaker does know the answer, and this has an effect on the wide scope behavior of such indefinites (see Section 5 and the more explicit elaboration of the whole theory in Onea 2016).

According to Onea, specialized indefinites evoke information about who can resolve the question raised by them. Aloni, on the other side, rather focuses on the semantic interaction of indefinites with other operators. These different perspectives highlight the numerous functions of indefinites (e.g. someone vs. a certain) and the need to account for them at different levels.

A further perspective on indefinites, more focused on the interface with syntax (both at the clausal level and word-internally), is explored by Kellert's and Poletto's contributions. Kellert's study, 'The evaluative meaning of the indefinite qualunque in (Old) Italian', investigates the historical evolution of a freechoice indefinite, similarly to Aloni. Kellert, however, concentrates on a particular aspect of this evolution: the emergence of a further, evaluative reading of the free-choice indefinite, which in certain contexts is interpreted as 'ordinary, average', as in una ragazza qualunque 'an ordinary girl'. This kind of reading has been observed for free-choice indefinites also in other languages, but it has never been investigated diachronically before.

First of all, Kellert defines the structural and interpretative prerequisites for the evaluative reading, showing that the potential ambiguity between a pure free-choice, a random-choice and an evaluative interpretation of qualunque is in fact resolved in context thanks to a number of principled differences in syntactic behavior (the evaluative reading strongly correlates with a postnominal, not determiner-like position for the indefinite) and in semantic-pragmatic requirements (the occurrence in episodic contexts and its ability to modify a nominal phrase introduced by a demonstrative). Secondly, the author shows how the diachronic emergence of the peculiar evaluative reading is dependent on the interplay with surrounding semantic operators, which are syntactically represented, notably negation and focus: the 'ordinary' reading emerges from the conventionalization of scalar inferences emerging in a focused negative context ('not just any' = 'ordinary', see further Section 6).

A special attention to the interplay between the quantifier's internal and external syntax is at the core of Poletto's study of the distribution of bare quantifiers at various historical stages of Italian ('Being bare: a survey of quantifier positions'). Bare quantifiers are pronominally used quantificational elements 
like Italian tutto / tutti 'all', molto 'much' / molti 'many', niente 'nothing'. According to Poletto, they have a different internal syntactic makeup with respect to full quantified nominal phrases. Namely, the QP does not take a NP as its complement, but a Classifier Phrase headed by an abstract classifier-like sortal noun (PERSON, THING, PLACE, TIME, WAY). Some grammaticalization processes are argued to provide evidence for the presence of phonetically realized counterparts of the abstract classifiers, as in the case of -ente 'being, thing' in Italian niente 'nothing', which is not etymologically transparent for contemporary speakers but would parallel more transparent elements like -thing and -body in e.g. nothing, everybody. This analysis has profound consequences for our understanding of so-called extended projections, that is, of the architecture of functional categories that compose the spine of DPs and QPs. In mainstream theory, they take a lexical category as a complement, and are inserted in order to add inflectional morphemes and perform information-structural operations. In Poletto's view, inspired by Kayne's work (see in particular a number of essays collected in Kayne 2005), also the core of the extended projection may be represented by a (potentially unpronounced) functional morpheme.

The internal makeup has an effect on the external syntax of these elements, since bare quantifiers reach positions in the clause that are not available to full quantifier phrases. This differential distribution is well known from French, where bare tout 'all' and rien 'nothing' in the direct-object function surface to the left of the past participle. Poletto investigates the distribution of the Italian analogous in Old Italian, where the position of the participle is comparable to that of Modern French, and in contemporary Italian, where the participle is higher in the clausal spine but a differential distribution for bare quantifiers is still detectable. She elaborates on the original proposal by Beghelli and Stowell (1997), who convincingly demonstrate that English quantifiers can access additional dedicated positions in the clause, and shows that a special positioning for bare quantifiers, higher than the position for normal direct and indirect objects, can be detected in Italian as well.

\section{Reference and Quantification in Discourse}

Reference and quantification are primarily investigated in the context of a sentence-both for syntactic as well as semantic reasons. Sentences are the basic unit for syntactic theorizing and models, hence models beyond the sentence boundary are often fuzzy and not in the core interest of syntacticians. For semanticists, the differences in the referential and quantificational structure 
can be best accounted for as differences in truth conditions or propositions - both are sentence bound. However, research in discourse anaphoric relations - starting with the donkey sentences of Geach (1962), E-type pronouns (Evans 1977), discourse referents (Karttunen 1976), and dynamic semantics as envisaged by Kamp (1981) and Heim (1982) — made obvious that anaphoric relations cannot be accounted for without the information provided by and inferred from context. More recently, the notion of questions appears to be crucial for understanding the discourse-semantic meaning of sentences and their referential expressions (Roberts 1996, Ciardelli, Groenendijk and Roelofsen 2019, Onea and Zimmermann 2019).

The chapters by Leonetti and Onea provide original contributions to the importance of discourse pragmatic principles for the interpretation of referential and quantificational expressions. Leonetti focuses on the interaction of syntactic, information structural and coherence principles for defining the licensing conditions of null subjects in Italian and Spanish. Onea models the function of indefinite noun phrases similarly to that of questions. He analyzes different types of indefinite pronouns as raising a question and then making different types of comments towards the content of the question. Both contributions show that referential and quantificational structures clearly extend beyond the sentence boundary and are important parameters for text structure.

Leonetti addresses the interaction between syntactic restrictions, information structure and discourse pragmatic coherence principles in his contribution 'Topics and the interpretation of referential null subjects'. Languages like Italian and Spanish allow for null subjects, while others like English or German do not. This is taken to be a central syntactic characteristic, which determines a class of so-called null subject languages (NSLs). Leonetti carefully develops an argument that shows that a purely syntactic theory of null subjects cannot account for the empirical data. He first presents a comprehensive set of syntactic data that are generally understood as showing that a null subject is anaphorically linked to (or licensed by) a topical antecedent. A topical expression, typically a subject, can license a null subject in a subsequent clause, while non-topical arguments must be taken up by personal pronouns or descriptive definite nominal phrases. Leonetti sketches then a recent syntactic theory of null subjects that is based on this set of widely accepted data: Frascarelli (2007, 2018) assumes an extension of the left periphery of the sentence and argues that a null subject is linked to a null topic phrase in this left periphery, which by itself must be licensed by a topical expression in the previous text. The null topic phrase can license the null subject and the question of licensing and interpretation of null subjects follows from syntactic principles. At a first glance, this 
theory seems to integrate information structural categories (topic) into the syntactic layout of the sentence and therefore links sentence structure to discourse structure.

However, Leonetti argues against this kind of theories with two main arguments. First, he shows that Frascarelli's theory has internal technical problems, as it does not state how to restrict the licensing of null topic phrases in the left periphery, which are the licensers of null subjects. But the theory also has an essential conceptual fault, as Leonetti argues: the theory neglects that null subjects can also be licensed by prominent non-topical antecedents, which create a higher coherence. In order to show this, Leonetti returns to the central empirical observation that seems to show that only topics (generally identical to subjects) license null subjects. He convincingly provides, for each of the data points, parallel examples that show that prominent non-topical constituents can license null subjects if they establish a more coherent discourse than the topical constituent. Prominence is defined as the relative ranking of arguments in the sense of Centering Theory (see Walker, Joshi and Prince 1998). There are several parameters that contribute to the prominence of an argument (see von Heusinger and Schumacher 2019 for a recent overview). Leonetti assumes that prominence depends on accessibility, i.e. syntactic structure (subject, subordinated clauses), and on information structure (topic, focus). Prominence is the main predictor (the central condition) for licensing null subjects, as it is for personal pronouns in non-null-subject languages. However, the independent semantic-pragmatic condition of coherence can overwrite this effect and license null subjects that are not prominent but contribute to a higher coherence of the discourse. Thus, Leonetti generalizes the interpretation of null subjects to broader principles of anaphora resolution, and he convincingly shows that this can only be modelled by the interaction of syntactic structure, information structure and general discourse pragmatic principles such as coherence.

Onea's contribution 'Specificity and questions of specification' complements the discussion of the role of discourse in licensing null subjects. Onea investigates different types of indefinite determiners such as a certain by embedding their semantics into a representation based on question semantics, a theory he terms 'erotetic theory of indefiniteness'. As introduced in Section 4, he assumes that an indefinite nominal phrase in a sentence like Ashanti saw a certain professor makes three kinds of contribution to the discourse: Firstly, all indefinites raise a specificational question, for our example: Which professor did Ashanti see? Secondly, the particular indefinite determiner makes a specific contribution, namely a comment on that question: Some salient agent knows the answer to that question. This salient agent is typically the speaker 
of the sentence. Thirdly, this comment on the question together with the regular assertion yields a contribution like Ashanti saw a professor and I know which professor. Onea can also show that the type of comment can be used to control the scopal properties of indefinite expressions. After introducing the semantic representation underlying the erotetic theory of indefiniteness he shows how this mechanism can capture even very subtle generalizations distinguishing different indefinite determiners. As test cases he analyzes the function of German ein gewisser vs. ein bestimmter (both 'a certain'), which differ in the way they select the salient agent that can identify the referent. Ein gewisser always selects the speaker of that sentence, while ein bestimmter can also select another salient agent in the discourse, as Ebert, Ebert and Hinterwimmer (2013) have convincingly shown.

Onea contributes new observations to this theory and develops a slightly different approach. He shows that both ein bestimmter and ein gewisser always take scope over at least one intensional operator, thus expressing specificity in the very original understanding (Ioup 1977). He further modifies the theory of Ebert, Ebert and Hinterwimmer (2013) by assuming that the salient discourse agent answers the specificational question (which professor?), rather than only identifying the referent without taking the noun phrase description into account. Thus, he can model the differences between the two indefinite determiners by assuming that distinct discourse agents can answer the relevant question. This view on indefinite reference is fundamentally discourse based and shows that reference and quantification can only be properly understood in a discourse model.

Interestingly, the discourse use of the indefinite can be shown to systematically correlate with the morphological presence, in its complex form, of an element that can also function as a discourse (modal or answer) particle, synchronically or diachronically (e.g. German bestimmt 'certainly', and other crosslinguistic parallels discussed in the paper).

\section{Reference and Quantification in Diachrony}

Diachronic research on reference and quantification has widely investigated how to interpret their role and, when relevant, their interplay in language change. The papers collected in this volume address this issue enriching the discussion with new perspectives on both articles (including partitives) and indefinites. We shall discuss the two dimensions in turn.

It is well known that, as concerns the development of indefinite articles, the complex question arises as to whether quantificational properties are lost 
when referential ones are acquired ${ }^{8}$-an issue which is of central importance in diachronic models as Givón's (1981) and Heine's (1997), among others. In his seminal contribution, Givón (1981: 50-51) proposed a "gradual scale of indefiniteness" which is composed of three (implicational) stages:

$$
\text { Quantification } \rightarrow \text { referentiality/denotation } \rightarrow \text { genericity/connotation }
$$

On the basis of the cline depicted above, ${ }^{9}$ the first step of grammaticalization of indefiniteness implies the change of the numeral 'one' into an indefinite marker through a process of semantic bleaching: when quantification is bleached out, the new indefinite marker is used to denote referential (that is, specific) indefinite nominals. Non-referentiality (including generics and predicatives) corresponds to the third and final stage of the grammaticalization cline, in which the indefinite marker extends its scope to all indefinite uses.

In the present collection, special attention is devoted to the grammaticalization of determiner systems, as well as to the grammaticalization of indefinites. As for determiners, a general suggestion emerging from the studies collected here is how the notion of 'cline' itself may be rethought if we consider the complexity of factors influencing the development and evolution of determiners. The contribution by Petrova provides a diachronic explanation for the use of predicative bare nouns in German which goes beyond traditional models of the grammaticalization of indefiniteness. An aspect that is at the core of Squartini's study is the issue of the grammaticalization paths from which different determiners arose in Romance languages. More specifically, he investigates to which extent classificational features of indefinite determiners, besides quantificational and referential ones, play a role in grammaticalization clines and how these features interact with morphosyntactic properties of number, which turns out to be another crucial factor. At many points Squartini refers to the well-known interplay between the robustness of number morphology and the availability of bare nouns with an indefinite interpretation. The interplay with number also emerges in Alexiadou's chapter in connection to the expression of genericity by means of bare nouns, comparing English with French. Alexiadou shares with Squartini the discussion on how the morphological expression of number may shape the evolution of determiners and the distribution of articles

8 See Lyons (1999: 89-95) for an overview; more recently, Frajzyngier (2011: 632-635).

9 On the notion of grammaticalization cline see Hopper and Traugott (2003: 6), who defined it as "a metaphor for the empirical observation that cross-linguistically forms tend to undergo the same kinds of changes", generally through different, related and (hypothetically) unidirectional stages (an issue discussed also in Aloni's study: see below). 
and bare nouns. The investigation of the diachronic processes through which bare nominals may become specialized for indefinite readings, eventually competing with articles, is another common thread in these three contributions to the volume, which confirm the importance of different diachronic forces at stake. We shall now deal with these issues in more detail.

Petrova's contribution challenges the traditional explanation of bare indefinites as an instance of incomplete grammaticalization provided by Givón's (1981) model. Languages with an indefinite article in which, nonetheless, bare nouns occur in predicative sentences should be considered as representing stage 2 in Givón's scale, namely, an intermediate stage. How can we account, then, for the alternation between bare nouns and indefinite nouns in predicative sentences? As seen in Section 3, Petrova's paper deals with this issue focusing on German noun phrases which occur as complements of copula verbs like sein 'be' and werden 'become'. Petrova reconstructs the diachronic paths which led to the situation of variation proper to present day standard German: here, as described in previous literature, the indefinite determiner is omitted in this type of predicative construction if a noun belongs to the category of 'role nouns' (Class A), giving rise to a bare variant, whereas it is expressed if a noun belongs to the category of 'class nouns' (Class B), although with many differences in the distribution when one looks at some contemporary dialects.

Through a corpus-based analysis of both quantitative and qualitative nature, Petrova investigates the behavior of nouns of Class A in predicative constructions within two distinct stages of German, with a particular regard to their dialectal distribution. In the first part of the paper, she shows how in both Early New High German and Middle High German Class A alternates between the bare variant and the variant with an indefinite determiner. Factors playing a role in the distribution are, in particular, the nature of appointment or position denoted and the specific social domain to which such an appointment/position belongs, the property of uniqueness of the denoted institutionalized roles (differently from present day standard German) and, in Middle High German, the non-referential status of the subject of the predicative sentence: uniqueness and non-referentiality favour the drop of the determiner. While this remains constant over time, what changes is the inventory of social roles corresponding to institutionalized activities, on the basis of extra-linguistic reasons. In conclusion, according to Petrova, the differences between the standard language and the dialects in the distribution of bare nouns and nouns introduced by an indefinite determiner in predicative sentences is not a matter of different degrees of grammaticalization, but is the consequence of a change driven by extra-linguistic factors and of a different syntactic feature in the language (presence or absence of empty determiners, as pointed out in Section 3). 
Special attention is paid to the historical development of indefiniteness also in the chapter by Squartini, who analyzes which forms and meanings the plural of the indefinite article may take in its development. As mentioned above, the quantificational properties of the indefinite article in the singular are expected in view of its cross-linguistically frequent diachronic source, the numeral 'one'. However, even more complicated is the situation in the plural of the indefinite article. According to some authors, the classificational dimension is also relevant there, a point that - as seen in Section 3 on the basis of Squartini's discussion-is more controversial in its interpretation. An important role in the discussion is played by the etymological source of the determiners themselves: different ways of cognitively apprehending plurality can explain the different diachronic sources for plural indefinite determiners. According to Herslund (2012), the 'partitive' form grammaticalized by some Romance languages is a determiner for mass also in the plural, whereas languages that use the plural of the numeral 'one' as the plural form of the indefinite determiner start its grammaticalization from uses where the form marks 'collectives' (sets of discrete entities), as can be observed in Old French. As Squartini puts it, two different evolutionary patterns are possible, which, in their historical starting point, reflect differences in the cognitive apprehension of referents: aggregates pattern formally either together with substances, or together with bounded entities. What Squartini's analysis also highlights for Romance is a form of "parasitism of plurals on singulars", in the sense that all indefinite plural determiners are the pluralized version of singular determiners; this also applies to zero marking, because, in the absence of an explicit determiner, plurality is expressed only through inflectional endings on the noun.

In his examination of the interaction of number and classificational aspects in Romance article systems, Squartini also discusses number marking on partitive articles taking the typological cline hypothesized by Bossong (2016) as a starting point. Squartini presents data from a lesser studied variety of Piedmontese, which, like some Occitan varieties, has 'bare partitives', that is, forms of de with no further morphological exponents. In Bossong (2016) bare partitives are interpreted as the third, namely intermediate, stage on the scale representing the diachronic process which leads to the obligatory use of the partitive article, as in Modern French. The scale would schematically look as follows (adapted from Bossong 2016: 69):

1. absence of any kind of partitive $\rightarrow 2$. minimal form of partitive $\rightarrow 3$. use of bare partitive (with no article) $\rightarrow$ 4. use of partitive + definite article $\rightarrow$ 5 . obligatory use of inflected partitive in almost all syntactic contexts 
Of particular interest from Squartini's perspective is the fact that in the analyzed Piedmontese variety, for the class of regular masculine nouns the lack of number marking on the partitive is accompanied by absence of number marking on the noun as well. In this case, according to the author's analysis, a neutralization of the formal distinction between mass and count nouns takes place, leading to a system modelled by what he defines as "the cognitive drive equating the apprehension of substances and aggregates". The opposite tendency is mirrored by the development of determiners in which plurals are clearly distinguished from masses, as for the Italian new multi-word expression (tutta) una serie di 'a (whole) series of', which arose from the grammaticalization of the noun serie, following in principle the same diachronic path from quantifier to determiner as the indefinite article un ' $a$ ' (although they show differences in their degree of grammaticalization). The fact that (tutta) una serie $d i$ is restricted to plurals inherently having a classificational value, since they refer to a set of bounded elements, and that number is not dismissed - on the contrary, it continues to be codified through inflectional endings on nounsis interpreted by Squartini as an incipient grammaticalization of classification in plurals, independently of the category of number.

This latter point connects to the diachronic role of number marking, which comes up in Alexiadou. Her chapter contains discussion of changing conditions on the generic interpretation of nominal phrases. First, she outlines the change affecting formally definite plural noun phrases in the history of English. Diachrony shows that the typological divide between languages that use plural bare nominals to express genericity and languages that adopt, instead, the definite article can be bridged by language change: Old English was much more similar to Romance in using plural nominal phrases with the definite article to express generic or kind reference. ${ }^{10}$ In addition, plural bare nouns were a possible alternative strategy. Moreover, earlier stages of English, which had richer number inflection, were similar to Modern German in allowing generic readings also for singular adjectival nominalizations: English the riche could be interpreted as 'the rich person', as German der Reiche. According to Allen (2010), the loss of this feature is connected to the loss of number inflection, which led the speakers to reinterpret the determiner + adjective sequence as plural by reason of the greater frequency of plural adjectival nominalizations in the language. Developments in the morphological expression of number are argued by Alexiadou to be responsible also for the second phenomenon of change

10 Alexiadou also discusses further aspects (syntax of possessives and adjectives) that show that the syntax of the Old English nominal phrase was in general closer to Romance. 
that she considers, by moving to the history of French. In Old French, both bare plurals and definite plurals were available strategies to express genericity, similarly to the Old English situation seen above. The trajectory of the change is, however, different in the two languages: in Modern French definite plural generics are retained, while the bare noun strategy is lost. In fact, bare nouns in French are lost completely, a gradual change that is diachronically connected to the loss of number morphology on nouns, which, as expected under Delfitto and Schroten's (1991) hypothesis, requires the presence of determiners to mark number in the DP.

As mentioned at the beginning of this section, this volume shows how also the domain of indefinites, besides articles, can provide insights into the motivation and the development of grammaticalization phenomena. A first clear observation emerging from the contributions dealing with the diachrony of indefinites (Aloni, Kellert) is that synchronic morphological complexity is frequent in indefinites and hints to a grammaticalization scenario. Both Aloni and Kellert, moreover, show how specialized forms of indefinites acquire their meaning contribution by integrating an originally optional pragmatic inference into the conventional meaning.

Aloni studies the diachrony of free-choice indefinites in Spanish and Dutch and shows how the historical data can help back up theoretical analyses. Specifically, for her case studies she argues that the association with the two abstract operators licensing the free-choice indefinite in its synchronic uses (the exhaustification operator exh and the universal quantifier $[\forall]$ ) can be traced back to the source of grammaticalization. The exh operator represents an inheritance from the original wh-morphology (cual- 'which' in Spanish cualquier and wie 'who' in Dutch wie dan ook), whereas universal quantification over propositional alternatives $[\forall]$ finds its origin in earlier universal readings of the construction (free relative clause or 'no matter' construction, analyzed as an unconditional) ultimately yielding the indefinite form.

A further original contribution of Aloni's study consists in detailing the stages of the grammaticalization process, where the syntactic aspects intertwine with the semantic ones. From the syntactic point of view, the grammaticalization consists in the loss of the autonomous clausal status of the free relative construction, which becomes part of the main clause. Semantically, the analysis proposes a path through which an originally conversational implicature becomes a conventional implicature and is later reanalyzed as part of the core conventional semantics. Crucially, the grammaticalization does not appear to be completely unidirectional, as is generally conceived of in grammaticalization clines, at least for some stages: the 'no matter' use is identified as the initial step of the grammaticalization of the Dutch free-choice indefi- 
nite, whereas it is the last step of the process in the case of the Spanish form. However, Aloni discusses how it might be plausible, on the basis of theoretical considerations, to conjecture that a 'no matter' use existed at earlier, undocumented stages of Spanish, subsequently disappeared and then emerged again more recently. This scenario opens up interesting perspectives for future comparative diachronic studies.

Interestingly, Kellert's analysis of the diachronic development of Italian free-choice indefinite qualunque shows some important similarities to Aloni's cases, witnessing to the usefulness of comparative approaches. Kellert dedicates her attention to a particular evaluative reading of qualunque, where the free-choice inference is lost, and the indefinite has a non-determiner-like use with the meaning 'ordinary'. The author shows how this use diachronically emerges from the conventionalization of an originally optional implicature in contexts where qualunque is found in negated and focused nominal phrases. In such contexts, the alternatives evoked by the indefinite are ranked according to a criterion of 'specialness', that is strikingness with respect to a pragmatically established value. The conventionalization of this meaning component, whose underlying mechanism is parallel to Aloni's cases, goes hand in hand with the fixation of the post-nominal positioning for qualunque. A further similarity with Aloni's case studies is represented by the diachronic role of the relative clause involved in the construction at the source of the diachronic process: data from Old Italian show that the post-nominal indefinite is originally part of a relative clause containing a subjunctive copula, which is later reduced, with the indefinite itself taking over a part of the construction's modal value, according to the author's analysis.

To conclude, consistently with the Invited Inferencing Theory of Semantic Change (Traugott 1999, Traugott and Dasher 2002), in which 'invited inferences' arising from contextual occurrences in the process of interaction between speaker and hearer are viewed as enabling grammaticalization, in both Aloni's and Kellert's chapters the context-dependency of change is recognized and a correlation is established between specific uses of a given form and the conventionalization of a new function.

\section{Conclusion}

In this introductory chapter, we have presented the main common research questions underlying the various contributions collected in this volume and we have summarized their main general results. We hope to have shown how theoretical and empirical considerations are inextricably tied and feed each other in 
this collection, as well as how the cross-linguistic and the diachronic perspectives can cooperate and be instrumental towards a better understanding of the complex systemic effects underlying the grammar of determiners and quantifiers. The presentation of the main issues discussed in this collection had also the goal of defending an integrated approach to grammar, in which syntactic and semantic hypotheses consistently go hand in hand in the theoretical modeling, and are always accompanied by pragmatic considerations. The latter are of paramount importance in accounting for the shape and the division of labor among modules of linguistic competence, from the choice between indefinite forms to the licensing and interpretation of null subjects. We saw the centrality of semantic and pragmatic mechanisms also in a diachronic perspective, in terms of the paradigmatic competition between forms but also in terms of the generation of systematic inferences that are subject to grammaticalization processes. In all these respects, the way ahead was paved by influential work in the past decades, which the contributions in this volume discuss and expand. As many chapters show, a particularly promising direction of research is represented by the combined diachronic and synchronic study of word-internal syntax and semantic compositionality, since morphologically complex forms (such as partitives or indefinites) can provide a hint not just to their historical origin, but also to their interrelations with other elements in the synchronic system.

\section{References}

Abney, Steven. 1987. The English noun phrase in its sentential aspect. Cambridge, MA: MIT PhD dissertation.

Aguilar-Guevara, Ana, Julia Pozas Loyo \& Violeta Vázquez-Rojas Maldonado (eds.). 2019. Definiteness across languages. Berlin: Language Science Press.

Alexiadou, Artemis, Liliane Haegeman \& Melita Stavrou. 2007. Noun phrase in the generative perspective. Berlin: de Gruyter.

Allen, Cynthia. 2010. Substantival adjectives in the history of English and the nature of syntactic change. In Rachel Hendery \& Jennifer Hendricks (eds.), Grammatical change: Theory and description, 9-25. Canberra: Pacific Linguistics.

Balogh, Kata, Anja Latrouite \& Robert D. Van Valin Jr. (eds.). 2020. Nominal anchoring: Specificity, definiteness and article systems across languages. Berlin: Language Science Press.

Barton, Dagmar, Nadine Kolb \& Tanja Kupisch. 2015. Definite article use with generic reference in German: An empirical study. Zeitschrift für Sprachwissenschaft 34(2). $147^{-173}$. 
Barwise, Jon \& Robin Cooper. 1981. Generalized Quantifiers and natural language. Linguistics and Philosophy 4. 159-219.

Beghelli, Filippo \& Tim Stowell. 1997. Distributivity and negation: The syntax of each and every. In Anna Szabolcsi (ed.), Ways of scope taking, 71-107. Dordrecht: Kluwer.

Borer, Hagit. 2005. In name only. Structuring sense, volume 1. Oxford: Oxford University Press.

Borik, Olga \& Berit Gehrke (eds.). 2015. The syntax and semantics of pseudo-incorporation. Leiden: Brill.

Borik, Olga \& M. Teresa Espinal. 2012. On definite kinds. Recherches linguistiques de Vincennes 41. 123-146.

Bošković, Željko. 2008. What will you have, DP or NP? In Emily Elfner \& Martin Walkow (eds.), Proceedings of NELS $37,101-114$. Amherst, MA: GLSA.

Bošković, Željko. 2012. On NPs and clauses. In Günther Grewendorf \& Thomas Ede Zimmermann (eds.), Discourse and grammar: From sentence types to lexical categories, 179-245. Berlin: de Gruyter.

Bossong, Georg. 2016. Classifications. In Adam Ledgeway \& Martin Maiden (eds.), The Oxford guide to the Romance languages, 63-72. Oxford: Oxford University Press.

Bruening, Benjamin, Xuyen Dinh \& Lan Kim. 2018. Selection, idioms, and the structure of nominal phrases with and without classifiers. Glossa: A Journal of General Linguistics 3(1, 42). 1-46.

Cabredo Hofherr, Patricia \& Anne Zribi-Hertz (eds.). 2014. Crosslinguistic studies on noun phrase structure and reference. Leiden: Brill.

Cardinaletti, Anna \& Giuliana Giusti. 1991. Partitive $n e$ and the QP hypothesis. A case study. University of Venice Working Papers in Linguistics 1. 1-19.

Cardinaletti, Anna \& Giuliana Giusti. 2018. Indefinite determiners: Variation and optionality in Italo-Romance. In Diego Pescarini \& Roberta D'Alessandro (eds.), Advances in Italian dialectology, $135^{-161 .}$ Leiden: Brill.

Carlson, Greg. 1977. A unified analysis of the English bare plural. Linguistics and Philosophy $1.413-457$.

Carlson, Greg, Rachel Sussman, Natalie Klein \& Michael Tanenhaus. 20o6. Weak definite noun phrases. In Christopher Davis, Amy Rose Deal \& Youri Zabbal (eds.), Proceedings of NELS ${ }_{3} 6,179-196$. Amherst, MA: GLSA.

Chierchia, Gennaro. 1998. Reference to kinds across languages. Natural Language Semantics 6. 339-405.

Chomsky, Noam, Ángel Gallego \& Dennis Ott. 2019. Generative Grammar and the faculty of language: Insights, questions, and challenges. Catalan Journal of Linguistics, 229-261. Special Issue 2019.

Ciardelli, Ivano, Jeroen Groenendijk \& Floris Roelofsen. 2019. Inquisitive semantics. Oxford: Oxford University Press. 
Dayal, Veneeta. 2011. Hindi pseudo-incorporation. Natural Language and Linguistic Theory 29. $123^{-167 .}$

Delfitto, Denis \& Jan Schroten. 1991. Bare plurals and the number affix in DP. Probus 3. $155^{-185}$.

Diesing, Molly. 1992. Indefinites. Cambridge, MA: MIT Press.

Ebert, Christian, Cornelia Ebert \& Stefan Hinterwimmer. 2013. The interpretation of the German specificity markers bestimmt and gewiss. In Cornelia Ebert \& Stefan Hinterwimmer (eds.), Different kinds of specificity across languages, 31-74. Berlin: Springer.

Evans, Gareth. 1977. Pronouns, quantifiers, relative clauses. Canadian Journal of Philosophy $7(4) \cdot 777-797$.

Fodor, Janet \& Ivan Sag. 1982. Referential and quantificational indefinites. Linguistics and Philosophy 5. $355^{-398 .}$

Frajzyngier, Zygmunt. 2011. Grammaticalization of reference system. In Bernd Heine \& Heiko Narrog (eds.), The Oxford handbook of grammaticalization, 625-635. Oxford: Oxford University Press.

Frascarelli, Mara. 2007. Subjects, topics, and the interpretation of referential pro. An interface approach to the linking of (null) pronouns. Natural Language and Linguistic Theory 25. 691-734.

Frascarelli, Mara. 2018. The interpretation of pro in consistent and partial NS languages: A comparative interface analysis. In Federica Cognola \& Jan Casalicchio (eds.), Null subjects in Generative Grammar, 211-239. Oxford: Oxford University Press.

Geach, Peter. 1962. Reference and generality. An examination of some medieval and modern theories. Ithaca, NY: Cornell University Press.

Giusti, Giuliana. 1991. The categorial status of quantified nominals. Linguistische Berichte $136.438-45^{2}$.

Givón, Talmy. 1981. On the development of the numeral 'one' as an indefinite marker. Folia Linguistica Historica $2.35-53$.

Grimshaw, Jane. 2005. Words and structure. Stanford: CSLI.

Haspelmath, Martin. 1997. Indefinite pronouns. Oxford: Oxford University Press.

Heim, Irene. 1982. The semantics of definite and indefinite noun phrases. Amherst, MA: University of Massachusetts PhD dissertation.

Heine, Bernd. 1997. Cognitive foundations of grammar. Oxford: Oxford University Press. Herslund, Michael. 2012. Grammaticalisation and the internal logic of the indefinite article. Folia Linguistica 46(2). 341-357.

von Heusinger, Klaus. 2002. Specificity and definiteness in sentence and discourse structure. Journal of Semantics 19(3). 245-274.

von Heusinger, Klaus. 2011. Specificity. In Klaus von Heusinger, Claudia Maienborn \& Paul Portner (eds.), Semantics. An international handbook of natural language meaning, volume 2, 1025-1058. Berlin: de Gruyter. 
von Heusinger, Klaus \& Petra B. Schumacher. 2019. Discourse prominence: Definition and application. Journal of Pragmatics 154. 117-127.

Higginbotham, James. 1985. On semantics. Linguistic Inquiry 16. 547-593.

Hopper, Paul \& Elizabeth Closs Traugott. 2003. Grammaticalization. Cambridge: Cambridge University Press.

Horrocks, Geoffrey \& Melita Stavrou. 1987. Bounding theory and Greek syntax: Evidence from wh-movement in NP. Journal of Linguistics 23. 79-108.

Ihsane, Tabea. 2008. The layered DP: Form and meaning of French indefinites. Amsterdam: Benjamins.

Ihsane, Tabea (ed.). 2021. Disentangling bare nouns and nominals introduced by a partitive article. Leiden: Brill.

Ioup, Georgette. 1977. Specificity and the interpretation of quantifiers. Linguistics and Philosophy 1. 233-245.

Kabatek, Johannes \& Albert Wall (eds.). 2013. New perspectives on bare noun phrases in Romance and beyond. Amsterdam: Benjamins.

Kamp, Hans. 1981. A theory of truth and semantic representation. In Jeroen Groenendijk, Theo M.V. Janssen \& Martin Stokhof (eds.), Formal methods in the study of language. Proceedings of the Third Amsterdam Colloquium, 277-322. Amsterdam: Mathematical Center. Reprinted 2013 in Klaus von Heusinger \& Alice ter Meulen (eds.), The dynamics of meaning and interpretation. Selected papers of Hans Kamp, 329-369. Leiden: Brill.

Karttunen, Lauri. 1976. Discourse referents. In James D. McCawley (ed.), Notes from the linguistic underground (Syntax and Semantics 6), 363-385. New York: Academic Press.

Kayne, Richard. 1994. The antisymmetry of syntax. Cambridge, MA: MIT Press.

Kayne, Richard. 2005. Movement and silence. Oxford: Oxford University Press.

Keenan, Edward \& Jonathan Stavi. 1986. A semantic characterization of natural language determiners. Linguistics and Philosophy 9(3). 253-326.

Klockmann, Heidi. 2020. The article $a(n)$ in English quantifying expressions: A default marker of cardinality. Glossa: A Journal of General Linguistics 5(1, 85).1-31.

Kratzer, Angelika \& Junko Shimoyama. 2002. Indeterminate pronouns: The view from Japanese. In Yukio Otsu (ed.), Proceedings of the Third Tokyo Conference on Psycholinguistics, 1-25. Tokyo: Hituzi Syobo.

Larson, Richard. 2019. The DP hypothesis and (a)symmetries between DP and CP. Linguistic Analysis 42(3-4). 507-548.

Leonetti, Manuel. 1999. El artículo. In Ignacio Bosque \& Violeta Demonte (eds.), Gramática descriptiva de la lengua española, volume 1, 787-89o. Madrid: Espasa.

Longobardi, Giuseppe. 1994. Reference and proper names: A theory of N movement in syntax and Logical Form. Linguistic Inquiry 25(4). 6o9-665.

Longobardi, Giuseppe. 2001. How comparative is semantics? A unified parametric theory of bare nouns and proper names. Natural Language Semantics 9. 335-369. 
Lyons, Christopher. 1999. Definiteness. Cambridge: Cambridge University Press.

Matthewson, Lisa. 2001. Quantification and the nature of crosslinguistic variation. Natural Language Semantics 9. 145-189.

Montague, Richard. 1973. The proper treatment of quantification in ordinary English. In Jaakko Hintikka, Patrick Suppes \& Julius M.E. Moravcsik (eds.), Approaches to natural language: Proceedings of the 1970 Stanford Workshop on Grammar and Semantics, 221-242. Dordrecht: Reidel.

Onea, Edgar. 2016. Potential questions at the semantics-pragmatics interface. Leiden: Brill.

Onea, Edgar \& Malte Zimmermann. 2019. Questions in discourse: An overview. In Klaus von Heusinger, Edgar Onea \& Malte Zimmermann (eds.), Questions in discourse, volume 1: Semantics, 5-117. Leiden: Brill.

Panagiotidis, Phoevos. 2018. Determiners. Oxford research encyclopedia of linguistics. Oxford: Oxford University Press.

Partee, Barbara H. 1987. Noun phrase interpretation and type-shifting principles. In Jeroen Groenendijk, Dick de Jongh \& Martin Stokhof (eds.), Studies in Discourse Representation Theory and the theory of Generalized Quantifiers, 115-143. Dordrecht: FORIS.

Perlmutter, David M. 1970. On the article in English. In Manfred Bierwisch \& Karl Erich Heidolph (eds.), Progress in linguistics: A collection of papers, 233-248. The Hague: Mouton.

Rijkhoff, Jan. 2002. The noun phrase. Oxford: Oxford University Press.

Roberts, Craige. 1996. Information structure in discourse: Towards an integrated formal theory of pragmatics. In Jae-Hak Yoon \& Andreas Kathol (eds.), Papers in semantics (Working Papers in Linguistics 49), 91-136. The Ohio State University. Reprinted 2012 in Semantics \& Pragmatics 5. 1-69.

Russell, Bertrand. 1905. On denoting. Mind 14. 479-493.

Schwarz, Florian. 2009. Two types of definites in natural language. Amherst, MA: University of Massachusetts $\mathrm{PhD}$ dissertation.

Schwarzschild, Roger. 2002. Singleton indefinites. Journal of Semantics 19. 289-314.

Shlonsky, Ur. 1991. Quantifiers as functional heads: A study of Quantifier Float in Hebrew. Lingua 84. 159-180.

Stark, Elisabeth, Elisabeth Leiss \& Werner Abraham (eds.). 2007. Nominal determination. Typology, context constraints, and historical emergence. Amsterdam: Benjamins.

Stowell, Tim. 1989. Subjects, specifiers, and X-Bar Theory. In Mark Baltin \& Anthony Kroch (eds.), Alternative conceptions of phrase structure, 232-262. Chicago: University of Chicago Press.

Stowell, Tim. 1991. Determiners in NP and DP. In Katherine Leffel \& Denis Bouchard (eds.), Views on phrase structure, 37-56. Berlin: Springer.

Strawson, Peter F. 1950. On referring. Mind 59. 320-344. 
Szabolcsi, Anna. 1983. The possessor that ran away from home. The Linguistic Review 3. 89-102.

Szabolcsi, Anna. 1987. Functional categories in the noun phrase. In István Kenesei (ed.), Approaches to Hungarian 2, 167-190. Szeged: JATE.

Traugott, Elizabeth Closs. 1999. The role of pragmatics in a theory of semantic change. In Jef Verschueren (ed.), Pragmatics in 1998: Selected papers from the 6th International Pragmatics Conference, volume 2, 93-102. Antwerp: International Pragmatics Association.

Traugott, Elizabeth Closs \& Richard B. Dasher. 2002. Regularity in semantic change. Cambridge: Cambridge University Press.

Walker, Marilyn A., Aravind K. Joshi \& Ellen F. Prince. 1998. Centering in naturally occurring discourse: An overview. In Marylin A. Walker, Aravind K. Joshi \& Ellen F. Prince (eds.), Centering Theory in discourse, 1-28. Oxford: Oxford University Press.

Williams, Edwin. 1983. Semantic vs. syntactic categories. Linguistics and Philosophy 6. $423-446$.

Zamparelli, Roberto. 200o. Layers in the Determiner Phrase. New York: Garland.

Zamparelli, Roberto. 2008. Bare predicate nominals in Romance languages. In Hendrik Høeg Müller \& Alex Klinge (eds.), Essays on nominal determination: From morphology to discourse management, 101-130. Amsterdam: Benjamins. 